\title{
Optimal user oriented multi-level experience planning strategy for electric automobile charging path
}

\author{
Wen Wang ${ }^{1}$, Xiaofeng Peng ${ }^{1}$, Jun Jia ${ }^{2, a}$, Ji Zhao ${ }^{2}$, Wei Xiao ${ }^{2}$, Shu $\mathrm{Su}^{1}$ \\ ${ }^{1}$ State Grid Electric Vehicle Service Co., Ltd., 100053 Beijing, China \\ 2 Tsinghua Sichuan Energy Internet Research Institute, 610042 Chengdu, China
}

\begin{abstract}
Focusing on the battery-charging problem that is brought to the electric automobile users, this paper integrated the "automobile-network-path" multi-source information and presented the multi-level user experience index system which combined charging prices, driving distances, degrees of traffic congestion and other factors. The recommended algorithm and model for charging strategy was built up to improve the user experience. Meanwhile, it invoked map Application Programming Interface (API) to plan multiple paths. Consolidated by the status of charging piles, the distance between the automobile and the piles, the charging prices along with more real-time information, the multi-level user oriented experience index system was set up to recommend an optimal navigation route to the charging station for the automobile owners. Validated by the application results, the proposed algorithm that helped navigate to the charging stations or piles can effectively solve the practical problems 1 such as difficulty in orienting the charging piles, waiting in lines, and high charging fees.
\end{abstract}

\section{Introduction}

To meet the new requirements on automobile industrial upgrading and green consumption, the Standing Committee of the State Council passed the "Development Plan of New Energy Vehicle Industry (2021-2035)[1] on Oct. 9, 2020. It specified that, the sales of new NEVs need amount to about $25 \%$ till 2025 . And as of 2035 , it aims to realize overall electrification for domestic public vehicles. However, until Sep 2020, there were only 1418 thousand sets[2] of charging infrastructure throughout China, which was nowhere near enough to support the long-range development of electric automobiles.

In the midst of charging, the automobile owners are often faced with difficulty in finding charging piles, waiting long in line, costly charging fees and other circumstances. Accordingly, the scholars presented a number of orderly charge control strategies [3] to solve the large-scale automobile battery-charging control problems. Nevertheless, the user-oriented charging path planning solutions which serve to improve the user experience are not commonly seen.

It requires to take into account various factors when providing the users with good experience of charging path proposals such as precisely evaluating the energy consumption of vehicles, utilizing multi-dimensional information for path planning as well as considering the personalized demands of users and more factors. As the smart Internet-connected automobiles develop, the coordinative processing of "automobile-network-path" has laid the foundation for acquisition of multilevel experience index. Liu Y [4] used ant colony algorithm to properly plan route and arrange charging strategy for the distributing tasks of pure electric automobiles. Focusing on the three different requirements of electric automobile on time efficiency, the lowest costs and temporarily emergent navigation on the roads, Zhang B [5] presented corresponding recommended strategies.

However, to date it is still blank for the charging navigation strategy that thinks over overall user experience. Otherwise, relatively more algorithms need accurate parameters of vehicles, roads, charging stations and piles to support; therefore, it is hard for large-scale promotion. Based upon multi-network data fusion technology, this paper raised the calculation flow of multilevel experience and comprehensive indexes including distances, duration, expenses and traffic congestion status. In addition, the calculation process has been validated.

\section{The optimal charge station recommendation and navigation strategy}

\subsection{Search and selection of available charging piles}

Shown in Figure 1, when the residual battery capacity was detected by system as insufficient to support the current journey, it would launch warning for battery charging; Or after the users sent requirement for charging, it would search the charging piles $\mathrm{X} \mathrm{km}$ along the way which was recommended by present map API. The system could expand the search scope in case of inadequate objectives

* Corresponding author: zhaoyangneepu@163.com 
were oriented. Then all the found charging piles would be analysed to determine whether they are workable. The unavailable stations including those under construction, the private charging piles, the special-purpose charging piles and else would be dismissed, while the available piles would be set as the destination. Adopted by our previous researching findings[6] to evaluate the remaining mileage, estimate whether the automobile of current conditions could arrive at this station. At last, it formed the collection of candidate charging piles/stations.

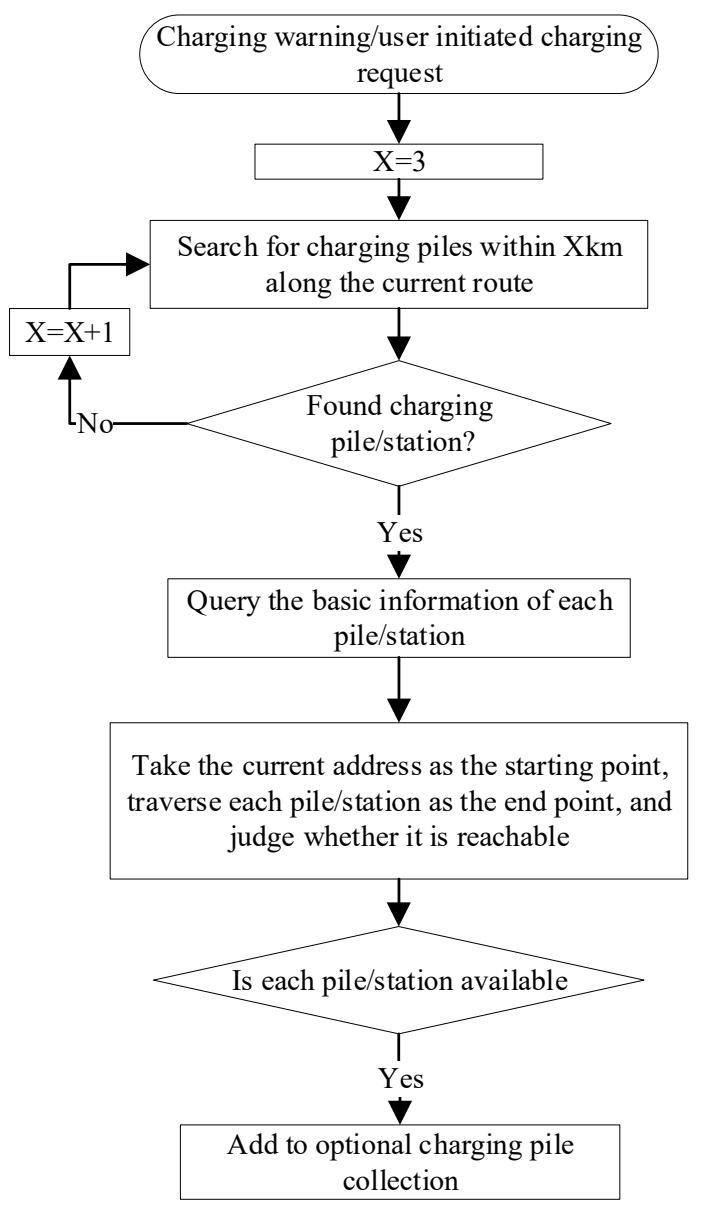

Figure 1. Optional charging station screening process.

\subsection{The user-oriented multilevel experience index system}

The indexes of experience mainly consist of distance, degree of traffic congestion, duration and expenses. Regarding the normal driving path without adding charging stations/piles as the basic parameter, the ratio of various parameters after the charging process was added versus the basic parameter was chosen as the measurement value of this index. To be specific:

(1). The index of distance $E_{d}$

$$
E_{d}=D_{c} / D_{b}
$$

Where $D_{b}$ represents the navigated driving distance from present location to the destination. $D_{c}$ represents the re-planned driving distance after setting the charging stations / piles as passing spots.
(2). The index of traffic congestion degree $E_{r}$

$$
E_{r}=D_{r} / D_{b}
$$

Where $D_{r}$ represents the equivalent congestion distance:

$$
D_{r}=\varepsilon_{1} \cdot D_{1}+\varepsilon_{2} \cdot D_{2}+\cdots+\varepsilon_{i} \cdot D_{i}
$$

Where $D_{i}$ stood for the distance of respective section in the path planning that was obtained by API; moreover $D_{c}=D_{1}+D_{2}+\cdots+D_{i}$ was the equivalent congestion coefficient. In accordance with the "Evaluation approach to road traffic congestion degree" [7], the corresponding relationship of various traffic conditions and the coefficient was shown in Table 1. Here it was defined as spending $\varepsilon$ times of driving time under congestion circumstances than that under normal traffic conditions. That is commonly known as "Several hundred meters' journey makes one feel like driving several kilometers."

Table 1. Road traffic congestion and $\varepsilon$

\begin{tabular}{|c|l|l|l|}
\hline $\begin{array}{l}\text { Road } \\
\text { condition }\end{array}$ & Amble & Congestion & $\begin{array}{l}\text { Severe } \\
\text { congestion }\end{array}$ \\
\hline $\boldsymbol{\varepsilon}$ & 1.2 & 1.5 & 2 \\
\hline
\end{tabular}

(3). The index of duration $E_{t}$

$$
E_{t}=t_{c} / t_{b}
$$

Where $t_{b}$ refers to the driving time from current location to the navigated destination and $t_{c}$ refers to the re-planned driving time after setting the charging piles / stations as the passing spots.

(4). The index of expenses $E_{f}$

$$
E_{f}=\left(f_{c}+f_{s}+f_{p}\right) / f_{b}
$$

Where $f_{b}$ represents the needed expenses for purchasing electricity as the market prices $(0.54 / \mathrm{kWh}), f_{c}$ refers to the charging expenses, $f_{s}$ refers to the service fees and $f_{p}$ refers to the parking fees.

By weighted summation on various kinds of factors, it obtained the multilevel experience index $I$, which was shown in Formula 10:

$$
I=E_{d} \cdot w_{d}+E_{r} \cdot w_{r}+E_{t} \cdot w_{t}+E_{f} \cdot w_{f}
$$

The initial weighted factors contain following types. They match different recommendations respectively, which was shown in Table 2.

Table 2. Initial weight factor settings of 5 recommendations

\begin{tabular}{|l|l|l|l|l|}
\hline Recommendations & $\boldsymbol{w}_{\boldsymbol{d}}$ & $\boldsymbol{w}_{\boldsymbol{r}}$ & $\boldsymbol{w}_{\boldsymbol{t}}$ & $\boldsymbol{w}_{\boldsymbol{f}}$ \\
\hline Default & 0.25 & 0.25 & 0.25 & 0.25 \\
\hline Money-saving & 0.2 & 0.2 & 0.2 & 0.4 \\
\hline Fastest & 0.2 & 0.2 & 0.4 & 0.2 \\
\hline Less congestion & 0.2 & 0.4 & 0.2 & 0.2 \\
\hline Shortest distance & 0.4 & 0.2 & 0.2 & 0.2 \\
\hline
\end{tabular}

For users who get to use it for the first time, they can decide to choose from more than five above given paths simultaneously. Furthermore, the weighting coefficient of currently selected path was recorded then generated into personalized recommendation scheme. In subsequent application, the users can select from six methods and each selecting result will be submitted to the users' personalized weight. Suppose the historical collection of personalization weights is $\left[w_{d}^{p}, w_{r}^{p} w_{t}^{p}, w_{f}^{p}\right]$ and the latest selected collection of weights is $\left[w_{d}^{n}, w_{r}^{n}, w_{t}^{n}, w_{f}^{n}\right]$, 
accumulate the two weights as $\left[w_{d}^{p}+w_{d}^{n}, w_{r}^{p}+\right.$ $\left.w_{r}^{n}, w_{t}^{p}+w_{t}^{n}, w_{f}^{p}+w_{f}^{n}\right]$ and then normalize this sequence to obtain the renewed personalized user weighting coefficient.

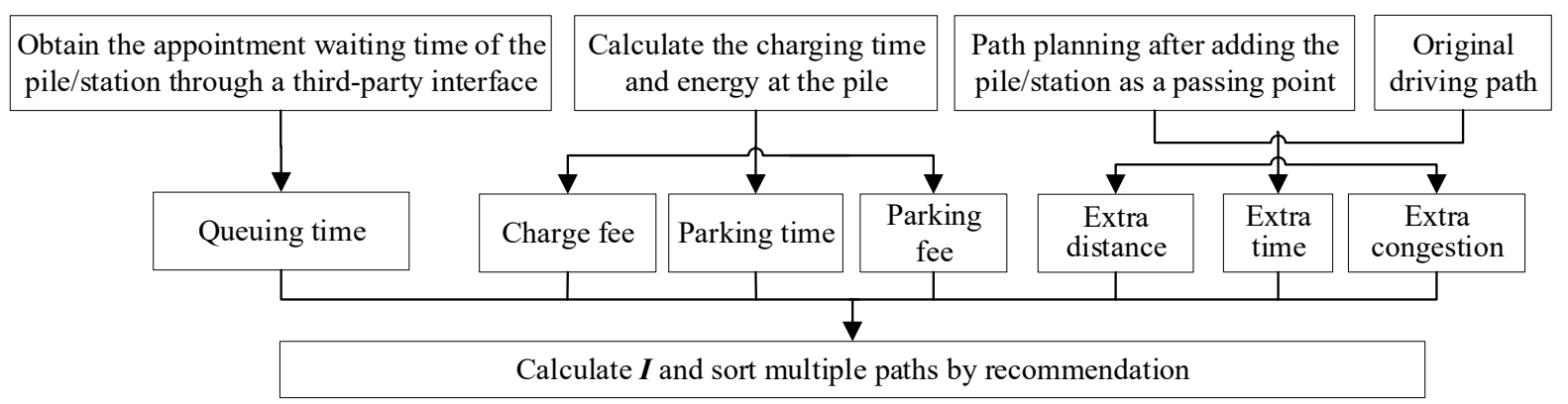

Figure 2. Flow chart of user-oriented multi-level experience indicators.

In case the charge navigation demand arose, the collection of candidate charging stations were primarily obtained in accordance with Figure 1. And then every charging pile/station in the collection was added as the passing spots successively. After that, it calculated the preferred path by AMAP API per Figure 2 and invoked the real-time information of the charging piles /stations from the enterprise interface as well as calculated the basic parameter of each index. When $I$ was calculated in engineering application, the users can check at the planning stage so as to remove their unfavorable methods. By this means, it only calculates according to the checked weight. This aims to reduce the calculation load. Among all kinds of recommendation methods, the minimal $I$ refers to the best charging option. At last the personalized weights of users are renewed in accordance with the weights which are chosen at this time and previously.

\section{Application cases}

One case analysis was given as below. After the car owner arrived at destination, in view of personal habits or subsequent travel demand, the expected state of charge (SOC) at destination couldn't be lower than $20 \%$. The automobile parameters and the user's demand were shown in Table 3:

Table 3. Vehicle parameters and user requirements

\begin{tabular}{|l|l|}
\hline Battery capacity & $50.83 \mathrm{kWh}$ \\
\hline $\begin{array}{l}\text { Maximum } \\
\text { power }\end{array}$ & $120 \mathrm{~kW}$ \\
\hline $\begin{array}{l}\text { Starting } \\
\text { point }\end{array}$ & Chengdu Science City \\
\hline Destination & $\begin{array}{l}\text { Sandaoyan Ancient Town, } \\
\text { Pixian County }\end{array}$ \\
\hline SOC at the starting point & $45 \%$ \\
\hline $\begin{array}{l}\text { Expected SOC } \\
\text { at destination }\end{array}$ & $20 \%$ \\
\hline
\end{tabular}

Used AMAP API to get the recommended path planning as shown in Figure 3:

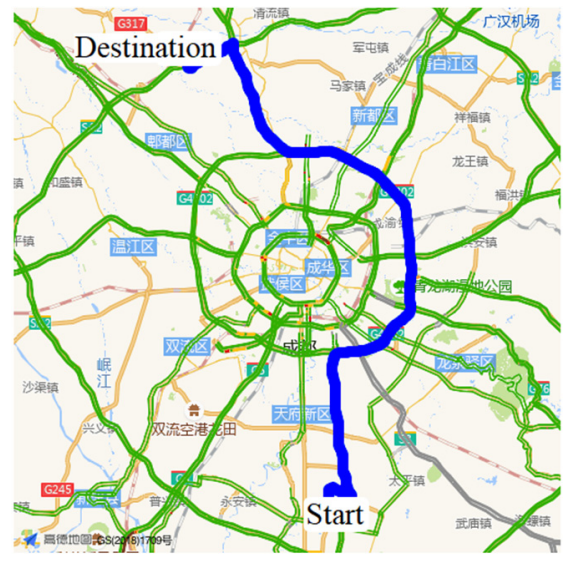

Figure 3. Recommended path obtained by Map API (the invoked time was 17:25 Oct. 28,2020 , non-working day)

By comparison of the balance driving mileage and driving distance under current battery status, it found that the automobile in this journey need charging on the way. Used the collection of candidate charging piles/stations which was built by searching flow in Chapter 3.1, three alternative charging stations were obtained as shown in Table 4:

Table 4. Candidate charging pile/station information

\begin{tabular}{|c|c|c|c|}
\hline $\begin{array}{l}\text { Charging } \\
\text { station }\end{array}$ & $\mathbf{A}$ & B & $\mathbf{C}$ \\
\hline Address & $\begin{array}{l}\text { XX, Lon } \\
\text { gquanyi } \\
\text { District, } \\
\text { Chengdu }\end{array}$ & $\begin{array}{l}\text { XX, Jinjiang Dis } \\
\text { trict, Chengdu }\end{array}$ & $\begin{array}{l}\text { XX, Jinjian } \\
\text { g District, } \\
\text { Chengdu }\end{array}$ \\
\hline $\begin{array}{l}\text { Charging } \\
\text { power }\end{array}$ & $\begin{array}{l}60 \mathrm{KW} \\
(500 \mathrm{~V})\end{array}$ & $7 \mathrm{KW}$ & $\begin{array}{l}120 \mathrm{KW} \\
(750 \mathrm{~V}) \\
\end{array}$ \\
\hline $\begin{array}{c}\text { Charging } \\
\text { fee( }(¥)\end{array}$ & $\begin{array}{l}00: 00 \sim 24: \\
00: 1.35\end{array}$ & $\begin{array}{l}00: 00-07: 00: 0.33 \\
07: 00-11: 00: 0.83 \\
11: 00-19: 00: 0.58 \\
19: 00-23: 00: 0.83 \\
23: 00-24: 00: 0.33\end{array}$ & Same as B \\
\hline $\begin{array}{c}\text { Service } \\
\text { charge( }(¥)\end{array}$ & $\begin{array}{c}0.6 ¥ / \mathrm{kW} \\
\mathrm{h}\end{array}$ & $0.8 ¥ / \mathrm{kWh}$ & $0.4 ¥ / \mathrm{kWh}$ \\
\hline $\begin{array}{c}\text { Parking fe } \\
\mathrm{e}(Y)\end{array}$ & $\begin{array}{c}\leq 3 \mathrm{~h}: 4 ¥ \\
>3 \mathrm{~h}: 1 ¥ / \\
\mathrm{h}\end{array}$ & Free & $\begin{array}{c}\leq 2 \mathrm{~h}: \text { free } \\
>2 \mathrm{~h}: 0.3 ¥ / \\
\text { min }\end{array}$ \\
\hline
\end{tabular}

Add above mentioned three charging stations successively and acquire three alternative navigation paths to the charging spots, which was shown in Figure 4. 


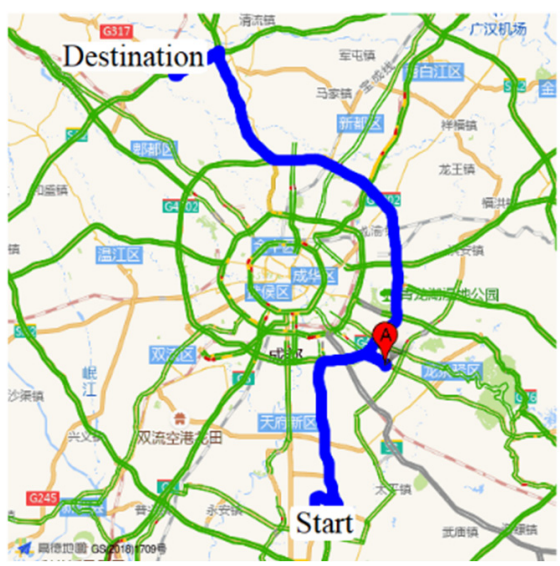

(a) Charging path 1 ;

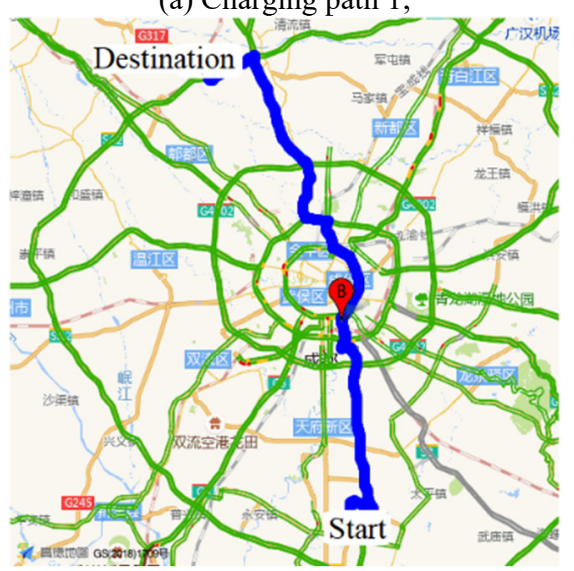

(b) Charging path 2;

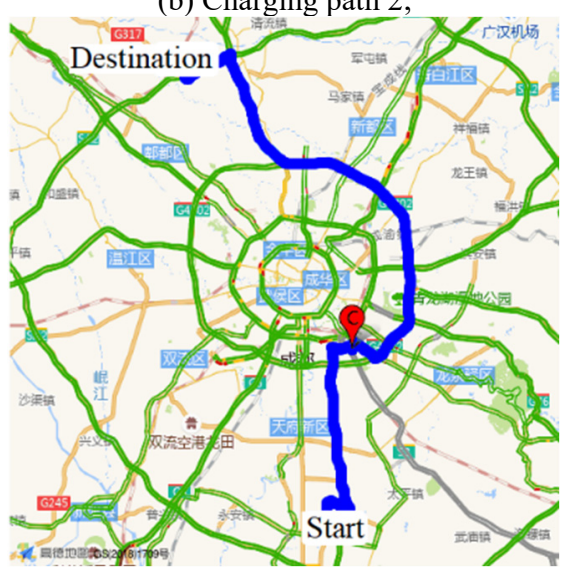

(c) Charging path 3

Figure 4. Three charging paths

Using the approaches from past research findings [6], the estimated SOC to each charge stations was respectively $30.0 \%, 31.4 \%$ and $29.4 \%$. Combined with the users' anticipated SOC at destination, It used Formula 7 and Formula 8 to calculate the charging capacity.

$$
\begin{aligned}
& E n_{\text {available }}=S O E_{\text {current }}-S O E_{\text {destination }} \\
& E n_{\text {charge }}=E n_{\text {pre }}-E n_{\text {available }}
\end{aligned}
$$

Where $\mathrm{SOE}_{\text {destination }}$ represents the state of energy (SOE for short) in accordance with SOC. SOE $\mathrm{Surrent}$ represents the acquired SOE[8] in the light of current SOC. $E n_{\text {available }}$ can be used to indicate the available energy after removing the users' expected remaining energy at destination. En pre refers to the evaluated energy consumption. En $n_{\text {charge }}$ refers to the current charging capacity. By consolidating the charging pile information and $E n_{\text {charge }}$, it can obtain the essential parameters including the charging expenses, charging duration and else.

As Figure 2 the indexes were respectively calculated. And the results were shown in Table 5. It could be seen that, the integrated performance index of the third solution was the best. To validate this recommended scheme, two SOCs which possessed the same model and battery capacity of around $45 \%$ set out in the meantime. EV1 adopted the optimal recommended scheme at this time; the scheme of EV2 was decided by the automobile owner. Finally, EV2 searched for charging piles nearby when its battery was nearly run out; it took a long time and inflecting process also arrived at the destination very late. Therefore, the experience of automobile owner is low. EV1 that adopted this scheme arrived at destination at expected time and its remaining SOC was $21.3 \%$. Consequently, it provided excellent travel experience for the automobile owners.

Table 5. Comparison of charging station solutions

\begin{tabular}{|l|l|l|l|}
\hline charging path & $\mathbf{1}$ & $\mathbf{2}$ & $\mathbf{3}$ \\
\hline distance & 94510 & 79258 & 90100 \\
\hline \multicolumn{1}{|c|}{$\boldsymbol{E}_{\boldsymbol{d}}$} & 1.04 & 0.87 & 0.99 \\
\hline$D_{\boldsymbol{r}}$ & 94795 & 80761 & 90308 \\
\hline \multicolumn{1}{|c|}{$\boldsymbol{F}_{\boldsymbol{r}}$} & 1.03 & 0.87 & 0.98 \\
\hline $\begin{array}{l}\text { New route driving } \\
\text { time (s) }\end{array}$ & 6971 & 6052 & 6258 \\
\hline $\begin{array}{l}\text { Estimated charging } \\
\text { time (s) }\end{array}$ & 424 & 1634 & 206 \\
\hline $\begin{array}{l}\text { Estimated queuing } \\
\text { time (s) }\end{array}$ & 0 & 600 & 0 \\
\hline Total duration (s) & 7395 & 8286 & 6464 \\
\hline \multicolumn{1}{|c|}{$\boldsymbol{E}_{\boldsymbol{t}}$} & 1.47 & 1.64 & 1.28 \\
\hline Charging fee (¥) & 9.55 & 1.84 & 3.99 \\
\hline Service fee (¥) & 4.25 & 2.54 & 2.75 \\
\hline Parking fee (¥) & 4 & 0 & 0 \\
\hline Total cost (¥) & 17.80 & 4.38 & 6.74 \\
\hline $\boldsymbol{E}_{\boldsymbol{f}}$ & 4.84 & 2.65 & 1.88 \\
\hline $\boldsymbol{I}$ & 2.09 & 1.51 & 1.28 \\
\hline
\end{tabular}

Ultimately, it is worth noting that, this case used AMAP API under specific range of time to invoke the needed information for the algorithm and offline test. Due to unduplicated factors such as road conditions, weather, driving habits and other elements, above mentioned calculation results are difficult to be reproduced.

\section{Conclusion}

Relying on the massive multisource data from the vehicles, charging piles and maps on new-energy automobile monitoring platform and the transportation, this paper integrated multisource information to build the useroriented multilevel experience index. It proposed the strategies for charge station recommendation and path planning which took into account the charging prices, the driving distances, the degree of traffic congestion and other factors. In the meantime, the self-adjustment 
solution was designed out to meet the personalized requirements on charging spots navigation.

In future, in the process of building multilevel experience indexes, the life and entertainment measures can be taken into account thus further improving the user experience.

\section{Acknowledgments}

The work is supported by Science and Technology Project of State Grid Corporation of China (5418-202018247A-00-00).

\section{References}

1. Official website of the Ministry of Industry and Information Technology. The Ministry of Industry and Information Technology held a kick-off meeting for the preparation of the "New Energy Automobile Industry Development Plan (2021-2035)" [J]. People's Public Transport, (2): 27-27 (2019)

2. National Energy Administration. Annual Report of China Electric Vehicle Charging Infrastructure Promotion Alliance [EB/OL]. http://www.nea.gov.cn/2017-6/19/c_136376732.html

3. Ou M, Chen Z, Tan Y, et al. Electric vehicle charging load optimization based on peak-valley time-of-use electricity price [J]. Journal of Electric Power Science and Technology, 35(05): 54-59 (2020)

4. Liu Y, Chen H. Distribution path planning and charging strategy of pure electric vehicles under load influence[J]. Computer Applications,40(10):28312837 (2020)

5. Zhang B, Liu X, Fan M. Optimization of vehicle charging path guidance in multiple demand scenarios[J]. Transportation Energy Conservation and Environmental Protection, 16(04): 22-27(2020)

6. Yan J, Xiao W, Jia J, et al. Remaining driving range data-driven algorithm based on energy consumption parameter identification and road condition prediction [J/OL]. Journal of Chongqing University of Technology (Natural Science): 1-13(2020)

7. Ministry of Public Security of the People's Republic of China, GA/T 115-2020 Road Traffic Congestion Degree Evaluation Method [S]. Beijing: China Standard Press, 2020.

8. Hu X, Feng F, Liu K. State estimation for advanced battery management: Key challenges and future trends[J]. Renewable \& Sustainable Energy Reviews, 114(OCT.):109334.1-109334.13(2019) 